\title{
Skill underutilization and under-skilling in Europe: The role of workplace discrimination
}

DOI:

$10.1177 / 0950017019865692$

\section{Document Version}

Accepted author manuscript

Link to publication record in Manchester Research Explorer

\section{Citation for published version (APA):}

Rafferty, A. (2020). Skill underutilization and under-skilling in Europe: The role of workplace discrimination. Work, Employment \& Society, 34(2), 317-335. https://doi.org/10.1177/0950017019865692

\section{Published in:}

Work, Employment \& Society

\section{Citing this paper}

Please note that where the full-text provided on Manchester Research Explorer is the Author Accepted Manuscript or Proof version this may differ from the final Published version. If citing, it is advised that you check and use the publisher's definitive version.

\section{General rights}

Copyright and moral rights for the publications made accessible in the Research Explorer are retained by the authors and/or other copyright owners and it is a condition of accessing publications that users recognise and abide by the legal requirements associated with these rights.

\section{Takedown policy}

If you believe that this document breaches copyright please refer to the University of Manchester's Takedown Procedures [http://man.ac.uk/04Y6Bo] or contact uml.scholarlycommunications@manchester.ac.uk providing relevant details, so we can investigate your claim.

\section{OPEN ACCESS}




\title{
Skill underutilization and under-skilling in Europe: The role of workplace discrimination
}

\author{
Anthony Rafferty
}

\section{Correspondence address:}

Dr. Anthony Rafferty, Senior Lecturer in Employment Studies

Work and Equalities Institute

Alliance Manchester Business School (AMBS), AMBS East (E25)

University of Manchester, Booth St East, Manchester, M156PB.

Email: anthony.rafferty@manchester.ac.uk

Tel: +44 1613063457

Key Words: age discrimination; gender differences; Inequality and discrimination; labour market; over-qualification; over-education; skill underutilization; racism; under-skilling. 
Biography: Dr. Anthony Rafferty is Senior Lecturer in Employment Studies and a member of the Work and Equalities Institute (WEI) at Alliance Manchester Business School (AMBS), University of Manchester. His research chiefly focuses on labour market inequalities and job quality issues. He has undertaken advisory or research consultancy roles for a variety of organisations including the UN International Labour Organisation (ILO), the European Institute for Gender Equality (EIGE), the UK Commission for Skills and Employment (UKCES), The European Foundation (Eurofound) and the House of Commons Work and Pensions Select Committee. 


\title{
Skill underutilization and under-skilling in Europe: The role of workplace discrimination
}

\begin{abstract}
This article examines the effects of discrimination based on race, ethnic background, nationality, religion, sex, age, disability and sexual orientation on skill under-utilization and under-skilling in 30 European countries using the European Working Conditions Survey. People who experienced a variety of forms of workplace discrimination were more likely to report over-skilling, defined as having skills for more demanding roles than required for their job. Paradoxically, some forms of labour market discrimination were also linked to underskilling where people report requiring more training to fulfil their job role. The findings are explained in terms of how discrimination in the labour market can have differential impacts on access to career progression and training opportunities across organisations. Differences between self-report and statistical estimates of discrimination are observed, holding potential broader implications for the interpretation of statistical models in discrimination research.
\end{abstract}

Key Words: age discrimination; gender differences; Inequality and discrimination; labour market; over-qualification; over-education; skill underutilization; racism; under-skilling. 


\section{Introduction}

Discrimination refers to the unequal treatment of people founded on their membership of a socially defined group, such as based on their sex, racial background, ethnicity, nationality, religion, social class, age, disability, sexual orientation, transsexuality, or transgender (Einarsdóttir et al., 2015; Pager and Shepherd, 2008; Prokic-Breuer and McManus, 2016; Whittle, 2012). The negative impact of discrimination on employment opportunities has been established through experimental field studies (Pager and Shepherd, 2008; Riach and Rich, 2002), survey research (Fevre et al., 2013; Khattab, 2009; Kingston et al., 2015) and in-depth qualitative work (Harris and Ogbonna, 2015; Healy et al., 2011; Hudson et al., 2017; MikMeyer, 2016). Discrimination can restrict access to employment, inhibit career progression, and limit wage growth (Brynin and Güveli, 2012; Tomaskovic-Devey et al., 2005). The experience of discrimination is also associated with poorer mental wellbeing (Gee et al., 2007).

As discrimination has itself negative effects on labour market progression it is probable that people who experience discriminatory barriers are more likely to be in jobs that do not match their capabilities. However, the extent to which discrimination causes skill underutilization remains unclear. For example, whereas some research suggests discrimination manifests as unexplained racial, ethnic or migrant "penalties" in overqualification (Sirkeci and Acik, 2018; Rafferty, 2012), other studies argue that wider between-group differences in quality of skills or other characteristics account for such differences (Kislev, 2016; Prokic-Breuer and McManus, 2016). Whether or not discrimination causes skill underutilization is important for a number of reasons. Compared to the better matched, people who are over-qualified for their jobs experience lower wages (Leuven and Oosterbeek, 2011), poorer job satisfaction (Green and Zhu, 2010) and greater 
depressive symptoms (Bracke et al., 2013). Over-qualified minority and migrant workers also have a higher risk of poverty (Thomas, 2015).

Existing research on skill-underutilization and discrimination however is limited in a number of respects. Firstly, most of the debate has focussed on racial, ethnic or migrant differences. Consequently, less is known about how discrimination related to other protected characteristics affects skill utilization (O’Reilly et al., 2015). Beyond the potential negative impact on individual well-being, how discrimination more broadly affects the opportunity for people to realise their potential in the labour market should be a concern for human resource managers and policymakers. A further limitation of past studies is that, largely due to survey limitations, direct or self-report measures of discrimination are not used. Discrimination instead is typically inferred from between-group differences or "penalties" that remain unexplained after applying statistical controls (Heath and Cheung, 2006; Johnston et al., 2010; Sirkeci and Acik, 2018). Broader criticism surrounding inferring discrimination from regression adjusted employment and wage gaps centres on how unmeasured factors beyond discrimination may contribute to such differences, rendering them open to wider interpretation (Pager and Shepherd, 2008; Rubery, Grimshaw, and Figueiredo, 2005; Blank et al., 2004).

This article consequently extends on prior work in a number of important ways. Firstly, it examines whether discrimination based upon a broad range of protected status related characteristics increases the risk of skill-underutilization; these being racial or ethnic background, religion, country of origin, sex, age, disability and sexual orientation. Secondly, rather than just inferring discrimination effects from unexplained gaps in over-qualification, self-report measures of both perceived discrimination and skill underutilization are used to provide a more direct test of hypotheses. Importantly, the findings yielded by this approach reveal some critical problems of inference in prior studies (e.g. Prokic-Breuer and McManus, 
2016; Kislev, 2016). The absence of an overall unexplained between-group difference it is shown does not necessarily imply the absence of labour market disadvantage among people who experience discrimination. Beyond the current context, potential wider implications for the broader interpretation of unexplained inter-group differences as evidence for the presence or absence of discrimination are discussed. Finally, given discrimination may affect training and developmental opportunities (Reskin and Bielby, 2005; Harris and Ogbonna, 2015), a further novel contribution of this article is to examine whether self-reported discrimination is also linked to the risk of under-skilling where employees state requiring more training to fulfil their current role.

\section{Background}

Skill underutilization or over-skilling refers to where people hold skills beyond those required to perform their job. In the absence of survey measures "over-qualification" or "occupational mismatch," where people are considered to hold qualifications in excess of those required for their job, is often taken as a measure of over-skilling. A growing body of work considers the potential impact of labour market discrimination on skills mismatches (Livingstone, 2017). To date, this research largely centres on disadvantages experienced by ethnic minorities or migrants (O'Reilly et al., 2015). Ethnic minorities have a higher risk of over-qualification and this finding holds for both migrant (Aleksynska and Tritah, 2013; Chiswick and Miller, 2009; Galgóczi and Leschke, 2016; Kler 2010; Prokic-Breuer and McManus, 2016; Reitz, 2001; Thomas, 2010, 2015) and domestic born populations (Johnston et al., 2010; Sirkeci and Acik, 2018; Rafferty, 2012, Dale et. al., 2008).

Although a broad range of experimental, survey-based and qualitative methodologies have been used to examine discrimination, one of the most common approaches to quantifying labour market effects centres on the identification of unexplained inter-group 
employment or wage gaps (Blank, Dabady, and Constance, 2004). Applying regression models to survey or administrative data, inference typically centres on the size of the coefficient for a between group difference after productivity related controls are deployed (Altonji and Blank, 1999) or decomposition methods that break down how differences in characteristics ("endowments") and the different effects for compared groups on labour market outcomes of such characteristics contribute to employment or wage gaps ${ }^{1}$ (e.g. Blinder, 1973; Oaxaca, 1973; Machado and Mata, 2005). Understanding the validity of these methods is important given their application across a diverse range of topics including labour market discrimination (e.g. Triventi, 2013) and access to public housing (Pager and Shepherd, 2008), as well as their application in government policy debates. Statistical evidence using regression-based estimates is also wildly used in legal expert testimonies as evidence for the presence or absence of discrimination (Antecol, Cobb-Clark and Helland, $2014)^{2}$

Past studies of ethnic or migrant differences in over-qualification rather than more directly identifying the effects of discrimination typically infer discrimination based on the presence of unexplained ethnic or migrant outcome gaps (Kislev, 2016; Prokic-Breuer and McManus, 2016; Sirkeci and Acik, 2018). A limitation with such approaches is that, even after accounting for observed characteristics, the extent to which remaining differences reflect discrimination is unclear given other factors may contribute to such gaps (Altonji and Blank, 1999; Pager and Shepherd, 2008). Regarding over-qualification, migrant barriers to occupational attainment could reflect unaccounted for differences in credentials or skills related to country of origin often unaccounted for in survey research. These may include the non-recognition of overseas qualifications and trade accreditations in a destination country (Kislev, 2016) or international variation in the quality of education received (Chiswick and Miller, 2009). Language ability also affects what types of jobs some migrants can obtain 
(Prokic-Breuer and McManus, 2016; Kislev, 2016), although discrimination related to aesthetical preferences for particular accents can also create disadvantages (Timming, 2016).

Access to job social networks or geographical location may further place migrants and native-born minorities at a disadvantage, although discrimination plays a role in shaping social capital differences both in and outside of the labour market (Hudson et al., 2017). Regarding domestic born minorities, qualification differences at the same level of certificate such as in subject studied, degree class achieved and the prestige of institution(s) attended could affect over-qualification risks, although institutionalised discrimination in the education system disadvantages educational access in the first place (Connor et al., 2004; Khattab, 2009).

Consequently, some researchers have raised a degree of scepticism regarding whether migrant or ethnic minority penalties actually reflect labour market discrimination (ProkicBreuer and McManus, 2016; Kislev, 2016). Prokic-Breuer and McManus (2016) for example discount the role discrimination plays in migrant over-qualification, arguing that in addition to language ability effects, migrants who may appear over-qualified for their job based upon their highest qualification level are not necessarily over-skilled in terms of cognitive skills related to quality of education received. Rather than discrimination, Kislev (2016) similarly argues that ethnic penalties across a range of employment outcomes can be explained in terms of country of origin and host country effects.

The interpretation of unexplained outcome gaps may therefore be fraught with inferential problems, although such issues are not confined to the study of over-qualification. A further and less considered matter of interpretation, however, concerns where no unexplained between group difference is found. The absence of an aggregate level between group outcome gap it is argued does not necessarily imply the absence of a discrimination 
effect. Relatedly, the negative effect discrimination exerts on an individual occurs regardless of whether population incidence and statistically estimated effect sizes are sufficient to reveal penalties at the aggregate level between broad socially constructed categories. The relationship between the subjective incidence of discrimination such as indicated by selfreport measures and that estimated by statistical models of unexplained gaps remains unclear. For example, whereas some authors suggest statistical approaches are unlikely to fully capture the nature and extent of discrimination (Kuhn, 1990), others suggest that, due to classification issues or the presence of indirect or covert discrimination, self-report based estimates of discrimination effects may be lower than when inferred from statistical employment or wage gaps (Antecol et al., 2014).

Sociological processes at the micro-level, partly due to broader complexity in causation, also do not necessarily aggregate up to simple directly comparable macro-level scenarios (Mouzelis, 2003). General social categories such as "migrants" are heterogenous in both their characteristics and labour market experiences, potentially rendering aggregate level descriptions difficult to interpret, thereby necessitating more fine-grained classifications (e.g. Khattab, 2009; Johnston et. al., 2010). For example, in some ethnic minority or migrant populations low levels of educational attainment or skills may preclude the risk of overqualification (i.e. it is harder to be over-qualified if you have no or few qualifications or skills), whereas other migrant groups with higher educational attainment have an above average risk of over-qualification (Rafferty, 2012). Simple aggregate comparisons between "migrants" and "non-migrants" may conceal such confounding differences. Consequently, assumptions regarding the sufficiency of statistical controls made to infer the presence of discrimination are also required to conclude the contrary where no inter-group difference is found ${ }^{3}$. 


\section{Theorising the role of discrimination}

More direct evidence is required on whether sub-populations who report experiencing discrimination exhibit labour market penalties. There are a number of reasons to expect that workplace discrimination across a range of protected characteristics leads to over-skilling. Firstly, discrimination may create difficulty in obtaining employment. Longer job search could lead to people taking on jobs below their skill levels to escape unemployment (Pager and Pedulla, 2015). Within employment, discrimination can limit career progression, restricting access to training and promotion opportunities. Allocative discrimination (Petersen and Saporta, 2004) occurs where women, minorities or other socially defined groups are sorted into different kinds of jobs through hiring, promotion and termination (Castilla, 2008). In the case of gender or racial characteristics, this can in part structure the labour market leading to both horizontal and vertical segmentation (Longarela, 2016). Allocative discrimination can occur as a result of stereotyping based on conscious or unconscious prejudices regarding the capabilities, personality traits or motivation levels of different socially defined groups, in-group preferences, out-group enmity, or through the sex or racial typing of work (Weller, 2016).

Various actors within organisations may be implicated in such discrimination. These include human resource managers, supervisors, or more senior managers, such as through setting organisational policies and the organisation of work. Qualitative research highlights how line managers can act as shop floor "gatekeepers" to recruitment, training, and progression opportunities (Harris and Ogbonna, 2015; Hudson et al., 2017). Harris and Ogbonna (2015: 65) apply social discrimination theory (Avery et al., 2008), which posits discrimination is shaped by the degree of social dissimilarity of a perpetrator from a target. Here the greater the social distance the higher the expected likelihood of line manager 
discrimination or "dissimilarity exclusion". As a result of in-group preferences, the patronage of gatekeepers can also facilitate "similarity inclusion" or social homophily, leading to privileged benefits for the more socially similar (Hudson et al., 2017). Beyond race and ethnicity, such similarity judgements can occur and intersect across a range of other social dimensions such as gender, social class, disability, or sexual orientation (Acker, 2006; Avery et al., 2008; Crenshaw, 1991).

Castilla (2008) illustrates how performance-reward biases may reflect in-group favouritism. Such biases may occur where in a merit-based reward system the performance of a discriminated against person even though judged as equal to an in-group member leads to lower level of reward. Peer effects and a broader climate of discriminatory attitudes can also shape line manager behaviour. Line managers may recruit, form teams, or promote on the basis of maintaining the homophily of a workforce demographic profile. This may be undertaken in a tacit acknowledgement of workforce prejudicial attitudes or of the expected negative response of current employees to increased diversity (Harris and Ogbonna, 2015; Kanter, 2008).

Hypothesis 1. People who experience workplace discrimination are more likely to experience skill underutilization.

The involvement and level of influence of line managers in recruitment, training access, and promotion likely varies between organisational contexts. This raises the possibility that within some contexts, line manager and other gatekeeper discrimination could manifest in terms of skill underutilization, whereas in others training deficits. Regarding the latter this could result from restricted access to formal training but also less informal on-thejob skill development (Shields and Price, 1999). For example, those receiving comparatively lower support or coaching from line managers could be less able to access informal training, 
inhibiting the transferal of firm-specific knowledge, skills or organisational capital (Tomaskovic-Devey et al., 2005). The effects of allocative discrimination may further occur in relation to the types of roles and jobs people are assigned to or through the formation of work groups, rotas and teams. This means discrimination may lead to some people being given less skill enhancing work that provides fewer learning opportunities (Castilla, 2008). Regarding gender differences, although empirical findings remain inconclusive (Dieckhoff and Steiber, 2011), employers may withhold investing in training for women or female dominated roles, such as based on the assumption that this investment will not be fully realised due to maternity related absence or the perceived lower commitment of part-time workers (Reskin and Bielby, 2005; Dämmrich et al., 2015).

Hypothesis 2. People who experience workplace discrimination are more likely to report under-skilling.

Individual-level prejudices and intergroup processes are therefore important to understanding how discrimination operates at the workplace. At the same time, discrimination reflects broader processes of history, ideology, power, oppression, culture and the attendant nature of social institutions, rendering it unsatisfactory to completely reduce explanations to psychological or micro-level interactive accounts (Noon, 2018; Reskin, 2005). Other perspectives consequently highlight how discrimination can be conceived to reflect broader social structures, or institutionalised practices, such as reflecting patriarchal, racial, or other inequality based societal norms and values that are embedded into economic, social and legal systems (Bonilla-Silva, 1997; Crenshaw, 1988; Feagin, 2013; Walby, 1989).

Such norms and values play out at the organizational level. Disparate impact, for example, concerns the occurrence of indirect discrimination where people are treated equally in relation to a set of rules but the rules are constructed to favour one group over another (e.g. 
"men" over "women," or "whites" over "blacks") (Pager and Shepherd, 2008). Consequently, even where a person acts without personal prejudice or unfavourable treatment (i.e. direct discrimination), indirect discrimination can occur where the following of an apparently neutral provision, criteria, or practice puts one group to a disadvantage without objective and legitimate justification (Zschirnt and Ruedin, 2016). Prior to labour market entry, indirect discrimination can also occur from school and university admission practices (Connor et. al., 2004). Within the workplace, the use of informal networks as a preferred recruitment route may lead to such discrimination due to homogeneity in social networks (Seidel et al., 2000). Recruitment and promotion policies regarding the value of overseas qualifications relative to domestic ones could also be a source of such bias where based on national or racial prejudices rather than systematic evaluation.

A sociologically and historically informed account of prejudice also guards against simplifying the causes and consequences of different forms of discrimination into a single unitary account. At the same time, insights from social psychological research highlight how discrimination and prejudices across dimensions may share similarities in terms of underlying social cognitive biases and stereotyping processes (Frederic and Falomir-Pichastor, 2018; Noon, 2018; O’Connor, 2017). A focus on gatekeepers (Harris and Ogbonna, 2015) also raises the possibility that there may be commonalities in the strategies and ways people enact varying prejudicial attitudes in the workplace (Pager and Shepherd, 2008). Furthermore, although different forms of prejudice are often treated as separate, they can be related or intersect through an underlying generalised ideology of inequality or group-based enmity, or in the manner in which they become institutionalised in organisational norms and practice (Acker, 2006; Healy et al., 2011; Zick et al., 2008). Zick et al. (2008) for example found that people who hold racist attitudes are also more likely to hold other discriminatory attitudes against women, homosexuality, or homeless people. Critically, such inter-relationships are 
manifest in right-wing populism both in the US and Europe, part of the electoral traction of which has been to relate different prejudices into a unitary discourse of social threat (Berlet and Lyons, 2018). The following empirical research consequently explores the effects of discrimination on skill utilization across a broad range of characteristics.

\section{Data and Methods}

The 2010 and 2015 European Working Conditions Surveys (EWCS) are used to provide a pooled sample of employees covering 30 countries $^{4}$. Pooling data from two years and across countries provides an adequate number of respondents to test the hypotheses $(N=59,555)$. The EWCS provides a unique source of information, containing self-report measures of skill underutilization, under-training and discrimination. For the outcome measure respondents are asked to select one of the following options: 1) "I need further training to cope well with my duties"; 2) "My present skills correspond well with my duties"; or 3) "I have the skills to cope with more demanding duties". This question provides a measure of both skill underutilization and under-skilling.

In terms of explanatory variables discrimination is measured on a series of questions regarding whether in the last 12 months at work respondents experienced discrimination linked to their race or ethnic background, religion, nationality, sex, age, disability or sexual orientation $(1=\mathrm{yes}, 0=\mathrm{no})$. An advantage of this method compared to an inter-group penalty approach is that it provides a more direct measure of discrimination. In terms of limitations, measures of perceived discrimination however rely on respondents identifying and classifying discrimination. The occurrence of more covert, implicit or "modern" discrimination (Noon, 2018) or the potentially ambiguous nature of indirect discrimination means self-report measures could underestimate discrimination (Pager and Shepherd, 2008; Gee et al., 2007). Self-report measures have some validity nonetheless in that they predict 
relevant outcomes such as poorer well-being and mental health (Gee et al., 2007; Kessler et al., 1999).

Given that the outcome variable has three categories, multi-level multinomial logistic regression ${ }^{5}$ was used. To examine the effects on between group differences of controlling for observable characteristics, average marginal effects are presented with and without controls. Separate models are estimated for each of the different forms of self-reported discrimination and the full coefficients for each model are reported in the online appendix. To draw comparisons to unexplained penalties approaches (Kislev, 2016; Prokic-Breuer and McManus, 2016; Sirkeci and Acik, 2018), estimates for migrant status, sex and age differences are further considered. A variable indicating job sex composition was also included in the model examining sex differences to consider whether people in female dominated industries experience greater training deficits such as due to the withholding of training.

One methodological issue regarding using nested non-linear models (e.g. multinomial logistic regression) is that due to the coefficients and error variance not being separately identified, scaling effects mean that changes in a coefficient of interest after introducing controls are not directly comparable. In solution to this problem the method proposed by Karlson et al., (2012) (KHB) is used to remove such effects. This allows for a more accurate decomposition of the percentage of a given unadjusted "total" gap into the confounding effects of observable characteristics ("indirect effects") and the "direct effects" of unexplained between group differences. In terms of control variables, occupation, industry, whether a person works in the public sector, highest qualification, job tenure (years), working hours, country and year were included in the models. Sex, age, and migrant status are further included in all models. 


\section{Findings}

Table 1 shows that women reported higher levels of discrimination than men, largely due to sex discrimination. The most commonly reported form of discrimination, however, was age discrimination, and this was the case for both men and women, whereas the least frequently reported was sexual orientation. Migrants were more likely to state experiencing discrimination than non-migrants with around $13 \%$ reporting some form of discrimination in the last 12 months compared to $6.7 \%$ of non-migrants. The most frequently reported discrimination against migrants was based on nationality $(7.2 \%)$ followed by racial or ethnic background $(6.7 \%)$.

\section{$<$ TABLE 1 HERE>}

With the exception of people who experienced disability-related discrimination, each of the considered forms of discrimination were associated with a higher level of skill underutilization (Table 2). The highest incidence was for discrimination based upon nationality, followed by racial or ethnic background. In terms of under-skilling, people who reported discrimination based upon disability, sex, age, sexual orientation, race, ethnic background and religion were more likely to report such a deficit than those reporting no discrimination. Several forms of discrimination were therefore associated with both a higher risk of skill under-utilization and a training deficit.

\section{$<$ TABLE 2 HERE >}

The effects of discrimination could manifest differently at varying parts of the lifecourse linked to levels of work experience and human capital, as could broader patterns of skill-utilization. The findings give some circumstantial support to the latter assertion, showing people under 25 years of age were more likely to report under-skilling than the other 
age groups. However, levels of skill underutilization were more similar across age groups with 25-34 year old respondents marginally reporting the highest levels. Table 3 further shows that age discrimination was not confined to older workers. Although the majority of people who reported such discrimination were over 45 years old (45\%), over 1 in 5 were below 25 years of age $(21.5 \%)$. Such discrimination was therefore apparent at both ends of the working-age spectrum but also for prime-age workers.

\section{<TABLE 3 HERE>}

\section{Multivariate analysis}

To facilitate comparisons to prior studies of migrant and ethnic penalties (Sirkeci and Acik, 2018; Prokic-Breuer and McManus, 2016) the multivariate analysis first considered whether unexplained penalties by migrant status exist after controlling for observed differences. After adjusting for other characteristics, migrants exhibited a small but statistically significant penalty in terms of skill underutilization (1.6\%) (Table 4). However, no significant difference was found in the risk of under-skilling between migrants and nonmigrants.

The findings regarding self-reported discrimination raise some important issues regarding inferring the presence or absence of discrimination from statistical models. Despite women overall having a lower probability of skill underutilization than men, of the different forms of discrimination, people who experienced sex discrimination (predominantly women) were the most likely to report skill underutilization. Such discrimination increased the probability of over-skilling by around 7.4\%. A similar finding was observed for underskilling where, despite women having a lower probability than men, people who reported sex discrimination had a higher risk. In both cases the impact of discrimination for the subpopulation that reported discrimination therefore occurred irrespective of aggregate level 
inter-group differences. Similarly, the penalties for those who reported discrimination based on their nationality $(+5.6 \%$ probability) and race or ethnicity $(+4.7 \%$ probability) were considerably higher than would be inferred from a broad migrant /non-migrant differences or "penalties" (+1.6\%). People who experienced age discrimination also had a higher probability of over-skilling.

\section{$<$ TABLE 4 HERE >}

In terms of self-reported training needs, all of the considered forms of perceived discrimination were associated with a greater risk of under-skilling. In relation to discrimination related to race, ethnicity, religion, or nationality, this finding was particularly notable, given after controlling for other factors the difference between migrants and nonmigrants was small and not statistically significant. People who reported discrimination related to disability reported the highest level of under-skilling $(+5.3 \%)$ followed by discrimination related to sexual orientation $(+4.9 \%)$. Although women overall had a lower risk of under-skilling than men, people who worked in female dominated jobs were marginally more likely to experience under-skilling $(+0.8 \%)$. Consistent with the view that skills mismatches may manifest in different ways across the life-course, after controlling for other factors people under the age of 25 years were the most likely to report under-skilling.

\section{$<$ TABLE 5 HERE >}

Using the KHB method, Table 5 breaks down the total unadjusted between group differences into direct and indirect effects. When statistical significance was assessed in terms of coefficients rather than average marginal effects statistically significant findings for discrimination linked to religious belief, disability and sexual orientation on the probability of skill under-utilisation were also found ${ }^{6}$. In terms of breaking down between group differences, around $30.4 \%$ of the total gap in skill under-utilization between migrants and 
non-migrants was explicable in terms of indirect effects. This suggests that a fairly large proportion of the albeit comparatively small migrant penalty in skill-underutilization was explicable in terms of differences in observed characteristics. In contrast, for the vast majority of the different self-report measures of discrimination direct effects were more contributory to differences.

Rather than "explain" part of the skill underutilization gap, controlling for individual differences actually increased the estimated penalty for people reporting disability related discrimination by around $15.7 \%$. This suggests that the observed characteristics of people reporting such discrimination positively reduced their risk of skill-utilization, concealing in the unadjusted comparisons the extent of penalty experienced ${ }^{7}$. Similarly, compared to comparisons unadjusted by statistical controls, women exhibited a lower risk of underskilling than men after such controls were applied although the overall difference between men and women remained small.

\section{Discussion}

Using data from over 30 European countries this article provides the first direct evidence of the impact of self-reported discrimination on skill-utilisation. It extends prior work by considering the effects of discrimination linked to a broad range of protected characteristics. After controlling for other differences, people who experience discrimination based upon their nationality, ethnic or racial background, sex, or age are more likely to report having skills to undertake more demanding work than their current role. The findings further suggest people who report discrimination based upon religious belief, disability or sexual orientation may also be at a greater risk of skill-underutilization. Paradoxically, all of the considered forms of perceived discrimination also increased the risk of under-skilling where people report require more training to adequately undertake their job. 
The article therefore makes a further novel contribution to literatures on skillutilization, showing how discrimination can also impact on under-skilling. One explanation of this finding is that, in addition to preventing people obtaining work that matches their skills, workplace discrimination also negatively effects training and broader skill development opportunities. This may occur for example where gatekeepers withhold opportunities from out-groups, give preference to supporting in-groups, or through indirect discrimination (Castilla, 2008; Harris and Ogbonna, 2015; Hudson et al., 2017). In this sense the effects of discrimination could manifest in divergent ways in different organisational settings linked to the specific power and resources of different prejudicial actors, but also to how different rules and practices produce varying patterns of opportunities and disadvantages (Pager and Shepherd, 2008).

Importantly, the findings also highlight how statistical and self-report measures of discrimination may produce divergent findings. However, rather than underestimating effects, the penalties estimated by self-report measures were typically higher than those suggested by between-group comparisons after controlling for statistical differences. For example, although women are less likely to report skill-underutilization than men, people who report sex discrimination are still more likely to experience over-skilling than those who do not. Similarly, the effect of discrimination on over-skilling, if inferred from a "migrant penalty" is considerably smaller compared to self-report estimates of the effects of discrimination based upon nationality, race, religion or ethnic background. The findings highlight how a separation may occur between aggregate level scenarios and the experience of discrimination within sub-populations reporting discrimination. Past research that discounts the relationship between discrimination and skill-underutilization based on the absence of aggregate statistical differences should therefore be interpreted cautiously. The absence of an overall betweengroup outcome gap does not necessarily imply the absence of discrimination. 
Despite being an important line of inquiry, given the ubiquitous use of statistical estimates of discrimination, a lack of self-report questions in major labour market surveys presents a limitation to further examining the correspondence between self-report and statistical estimates of discrimination in relation to other employment outcomes and wages (Habtegiorgis and Paradies, 2013). In the absence of such measures, research on discrimination and migration could focus on more fined grained population groups, such as to avoid broad categorisations between migrants and non-migrants (e.g. Khattab, 2009; Johnston et. al., 2010; Rafferty, 2012), although such an approach again is subject to questionnaire item availability, and sample sizes. Within the European Union, for example, a variety of historical reasons mean considerable variation exists between countries in the extent of statistical reporting in relation to the identification and circumstances of ethnic minority and migrant groups (Farkas, 2017).

\section{Conclusions}

The findings of this article demonstrate the impact of discrimination across a broad range of characteristics on the risk of skill under-utilization and under-skilling. One limitation that could be addressed by future research is to understand why some forms of discrimination are more likely to manifest as skill-underutilization whereas others under-skilling. Although there may be commonalities in underlying social and cognitive processes (Noon, 2018), differences in how varying forms of discrimination are enacted in the labour market by perpetrators or experienced by victims need to be more fully understood. At the same time there is a need for greater research that seeks to theoretical and empirical examine interrelationships given potential intersectionality between varying dimensions of labour market discrimination (Healy et. al, 2011). Given the timing of the survey it is also unclear whether the 2008/9 economic crisis affected the incidence of skill-underutilization. 
Further research is also required to understand the extent to which the divergence observed between statistical gap and self-report estimates of discrimination holds implications for the study of other employment or wage gaps, particularly where standard regression or decomposition methods are used. There are also potential implications to the weight that should be given in legal cases to statistical evidence of discrimination, or more importantly the lack thereof in the findings of expert testimonies (Antecol et al., 2014). It may be of little consolation to the victims of discrimination to know that on balance an organization is more egalitarian than their own experience, particularly where aggregate level statistics fail to illuminate or may conceal genuine problems.

\section{NOTES}

1. Methods using adjusted coefficients from regression models to estimate unexplained penalties typically use single equation frameworks, whereas Blinder-Oaxaca decomposition methods estimate separate regression equations for compared groups. The first approach therefore assumes that the returns to different "endowments" are the same for compared groups, whereas the latter estimates separate coefficients for each group for controls (Blank et al., 2004). A focus is placed on the former approach given this is most common in studies of ethnic and migrant penalties in overqualification.

2. For example, see EU Council Directive 2000/43/E.

3. Critiques of employment penalties and decomposition methods consider how the introduction of unmeasured variables could reduce the size of unexplained differences. An issue less considered is that of suppression effects; that some variables introduced could increase the size of penalties (MacKinnon et al., 2000).

4. See Online Appendix Table A1 for a full list of countries. 
5. An issue raised with multinomial logit models concerns the independence of irrelevant alternatives (IIA) assumption. In the current analysis, respondents are not choosing between outcomes categories and outcomes are dissimilar and not substitutable alternatives. The reliability of IIA tests is furthermore debated (Long and Freese, 2014: 408).

6. The calculation for statistical significance for average marginal effects and coefficients differs due to differences in the derivation of the estimates and standard errors (Long and Freese, 2014).

7. This can be interpreted as a suppression effect of the control variables on the estimate (MacKinnon et al., 2000).

\section{BIBILIOGRAPHY}

Acker J (2006) Class questions: Feminist answers. Maryland: Rowman and Littlefield.

Aleksynska M and Tritah A (2013) Occupation-education mismatch of immigrant workers in Europe: Context and policies. Economics of Education Review 36: 229-244.

Altonji JG and Blank RM (1999) Race and gender in the labor market. Handbook of Labor Economics 3: 3143-3259.

Antecol H, Cobb-Clark DA and Helland E (2014) Bias in the legal profession: Self-assessed versus statistical measures of discrimination. The Journal of Legal Studies 43(2): 32357.

Avery DR, McKay PF and Wilson DC (2008) What are the odds? How demographic similarity affects the prevalence of perceived employment discrimination. Journal of Applied Psychology 93(2): 235.

Berlet C and Lyons MN (2018) Right-wing populism in America: Too close for comfort. New York: Guilford Publications.

Blank RM, Dabady M and Constance C (2004) Measuring Racial Discrimination. Washington DC: National Academies Press.

Blinder AS (1973) Wage discrimination: reduced form and structural estimates. Journal of Human Resources 8(2): 436-455. 
Bonilla-Silva E (1997) Rethinking racism: Toward a structural interpretation. American Sociological Review 62(3): 465-480.

Bracke P, Pattyn E and dem Knesebeck O. (2013) Overeducation and depressive symptoms: diminishing mental health returns to education. Sociology of Health and Illness 35(8):1242-1259.

Brynin M and Güveli A (2012) Understanding the ethnic pay gap in Britain. Work, Employment and Society 26(4): 574-587.

Castilla EJ (2008) Gender, race, and meritocracy in organizational careers. American Journal of Sociology 113(6): 1479-1526.

Chiswick BR and Miller PW (2009) The international transferability of immigrants' human capital. Economics of Education Review 28(2): 162-169.

Connor H, Tyers C, Modood T and Hillage J (2004) Why the difference? A closer look at higher education minority ethnic students and graduates. Institute for Employment Studies research report 552.

Crenshaw KW (1988) Race, reform, and retrenchment: Transformation and legitimation in antidiscrimination law. Harvard Law Review 101(7): 1331-1387.

Crenshaw KW (1991) Race, gender, and sexual harassment. Southern California Legal Review 65: 1467-1476.

Dale A, Lindley J, Dex S \& Rafferty A. 2008, Women and Employment: Changing Lives and New Challenges|Women and Employ.: Changing Lives and New Challenges. 1 ed. Cheltenham: Edward Elgar Publishing, p. 81-106.

Dämmrich J, Kosyakova Y and Blossfeld HP (2015) Gender and job-related non-formal training: A comparison of 20 countries. International Journal of Comparative Sociology 56(6): 433-459.

Dieckhoff M and Steiber N (2011) A re-assessment of common theoretical approaches to explain gender differences in continuing training participation. British Journal of Industrial Relations 49(1): s135-s157.

Einarsdóttir A, Hoel H and Lewis D (2015) 'It's nothing personal': Anti-homosexuality in the British workplace. Sociology 49(6): 1183-1199.

Farkas L (2017) Data collection in the field of ethnicity. Analysis and comparative review of data collection practices in the EU. European Commission DG for Justice and Consumers.

Feagin J (2013) Systemic racism: A theory of oppression. London: Routledge.

Fevre R, Robinson A, Lewis D and Jones, T. (2013) The ill-treatment of employees with disabilities in British workplaces. Work, Employment and Society 27(2): 288-307.

Frederic NS and Falomir-Pichastor JM. (2018) Heterogeneity of ingroup identity and antiImmigrant prejudice: The moderating role of RWA and outgroup homogeneity. International Review of Social Psychology 31(1): 1-12. 
Galgóczi B and Leschke J (2016) EU labour migration in troubled times: skills mismatch, return and policy responses. London: Routledge.

Gee GC, Pavalko EK and Long JS (2007) Age, cohort and perceived age discrimination: using the life course to assess self-reported age discrimination. Social Forces 86(1): 265-290.

Green F and Zhu Y (2010) Overqualification, job dissatisfaction, and increasing dispersion in the returns to graduate education. Oxford Economic Papers 62(4): 740-763.

Habtegiorgis AE and Paradies Y (2013) Utilising self-report data to measure racial discrimination in the labour market. Australian Journal of Labour Economics 16(1): 5.

Harris LC and Ogbonna E (2015) Ethnic gatekeeping on the shopfloor: a study of bases, motives and approaches. Work, Employment and Society 30(1): 59-76.

Healy G, Bradley H and Forson, C (2011) Intersectional sensibilities in analysing inequality regimes in public sector organizations. Gender, Work and Organization 18(5): 467487.

Heath A and Cheung SY (2006) Ethnic penalties in the labour market: Employers and discrimination. DWP Research Report No 341. Sheffield: DWP.

Hudson M, Netto G, Noon M, Sosenko F, de Lima P and Kamenou-Aigbekaen N (2017) Ethnicity and low wage traps: favouritism, homosocial reproduction and economic marginalization. Work, Employment and Society 31(6): 992-1009.

Johnston R, Sirkeci I, Khattab N and Modood T. (2010) Ethno-religious categories and measuring occupational attainment in relation to education in England and Wales: a multilevel analysis. Environment and Planning A 42(3): 578-591.

Kanter RM (2008) Men and women of the corporation: New edition. New York: Basic Books.

Karlson KB, Holm A and Breen R (2012) Comparing Regression Coefficients Between Same-sample Nested Models Using Logit and Probit. Sociological Methodology 42(1): 286-313.

Kessler RC, Mickelson KD and Williams DR (1999) The prevalence, distribution, and mental health correlates of perceived discrimination in the United States. Journal of Health and Social Behavior 40(3): 208-230.

Khattab N (2009) Ethno-religious background as a determinant of educational and occupational attainment in Britain. Sociology 43(2): 304-322.

Kuhn P (1990) Sex Discrimination in Labor Markets: The Role of Statistical Evidence: Reply. American Economic Review 80(1):290-97.

Kislev E (2016) Deciphering the 'ethnic penalty' of immigrants in Western Europe: A crossclassified multilevel analysis. Social Indicators Research 134(2): 725-745.

Kler P (2010) Graduate overeducation and its effects among recently arrived immigrants to Australia: A longitudinal survey. International Migration 11(5): 383-340. 
Leuven E and Oosterbeek H (2011) Overeducation and mismatch in the labor market. In Hanushek EA, Machin S, Woessmann L (eds) Handbook of the Economics of Education (Vol. 4, pp.) Amsterdam: Elsevier, 283-326.

Livingstone D (2017) Skill under-utilization. In Warhurst C, Mayhew K, Finegold D and Buchanan J (eds) The Oxford Handbook of Skills and Training. Oxford: OU Press, 281-301.

Long JS and Freese J (2014) Regression models for categorical dependent variables using Stata, Third Edition. Texas: Stata Press.

Longarela IR (2016) Explaining vertical gender segregation: a research agenda. Work, Employment and Society 31(5): 861-871.

Machado JAF and Mata J (2005) Counterfactual Decomposition of Changes in Wage Distributions using Quantile Regression. Journal of Applied Econometrics 20(4):44565.

MacKinnon DP, Krull JL and Lockwood, CM (2000) Equivalence of the mediation, confounding and suppression effect. Prevention Science, 1(4): 173-181.

Mik-Meyer N (2016) Disability and 'care': managers, employees and colleagues with impairments negotiating the social order of disability. Work, Employment and Society 30(6): 984-999.

Mouzelis N (2003) Sociological theory: what went wrong?: diagnosis and remedies: Routledge.

Noon M (2018) Pointless diversity training: Unconscious bias, new racism and agency. Work, Employment and Society 32(1): 198-209.

O’Connor A (2017) The Nature of Prejudice. London: Macat Library.

O’Reilly J, Eichhorst W, Gábos A, Hadjivassiliou K, Lain D, Leschke J et al. (2015) Five characteristics of youth unemployment in Europe. SAGE Open 5(1): 1-19.

Oaxaca R (1973) Male-female wage differentials in urban labor markets. International Economic Review 14(3): 693-709.

Pager D and Pedulla DS (2015) Race, self-selection, and the job search process. American Journal of Sociology 120(4): 1005-1054.

Pager D and Shepherd H (2008) The sociology of discrimination: Racial discrimination in employment, housing, credit, and consumer markets. Annual Review of Sociology 34: 181-209.

Petersen T and Saporta I (2004) The opportunity structure for discrimination. American Journal of Sociology 109(4): 852-901.

Prokic-Breuer T and McManus PA (2016) Immigrant educational mismatch in Western Europe, apparent or real? European Sociological Review 32(3): 411-438.

Rafferty A (2012) Ethnic penalties in graduate level over-education, unemployment and wages: evidence from Britain. Work, Employment and Society, 26(6), 987-1006. 
Reskin B (2005) Including mechanisms in our models of ascriptive inequality. In Nielsen LB, Nelson, RL (eds) Handbook of employment discrimination research. Dordrecht: Springer, 75-97.

Reskin BF and Bielby DD (2005) A sociological perspective on gender and career outcomes. Journal of Economic Perspectives, 19(1): 71-86.

Riach PA and Rich J (2002) Field experiments of discrimination in the market place. The Economic Journal 112(483): F480-518.

Rubery J, Grimshaw D and Figueiredo H (2005) How to close the gender pay gap in Europe: towards the gender mainstreaming of pay policy. Industrial Relations Journal 36(3): 184-213.

Sirkeci I and Acik N (2018) Barriers for highly qualified A8 immigrants in the UK labour market. Work, Employment and Society 32(5): 906-924.

Seidel MDL, Polzer JT and Stewart KJ (2000) Friends in high places: The effects of social networks on discrimination in salary negotiations. Administrative Science Quarterly 45(1): $1-24$.

Shields MA and Price SW (1999) Ethnic differences in British employer-funded on and offthe-job training. Applied Economics Letters 6(7): 421-429.

Thomas KJ (2010) Racial and ethnic disparities in education-occupation mismatch status among immigrants in South Africa and the United States. Journal of International Migration and Integration/Revue de l'integration et de la migration internationale 11(4): 383-401.

Thomas KJ (2015) Occupational stratification, job-mismatches, and child poverty: understanding the disadvantage of Black immigrants in the US. Social Science Research 50: 203-216.

Timming AR (2016) The effect of foreign accent on employability: a study of the aural dimensions of aesthetic labour in customer-facing and non-customer-facing jobs. Work, Employment and Society 31(3): 409-428.

Tomaskovic-Devey D, Thomas M and Johnson K (2005) Race and the accumulation of human capital across the career: A theoretical model and fixed-effects application. American Journal of Sociology 111(1): 58-89.

Triventi M (2013) The gender wage gap and its institutional context: a comparative analysis of European graduates. Work, Employment and Society 27(4): 563-580.

Walby S (1989) Theorising patriarchy. Sociology 23(2): 213-234.

Weller SA (2016) Discrimination, labour markets and the labour market prospects of older workers: what can a legal case teach us? Work, Employment and Society 21(3): 417437.

Whittle S (2012) Respect and equality: Transsexual and transgender rights. London: Routledge-Cavendish. 
Zick A, Wolf C, Küpper B, Davidov E, Schmidt P and Heitmeyer W (2008) The syndrome of group-focused enmity: The interrelation of prejudices tested with multiple crosssectional and panel data. Journal of Social Issues 64(2): 363-383.

Zschirnt E and Ruedin D (2016) Ethnic discrimination in hiring decisions: a meta-analysis of correspondence tests 1990-2015. Journal of Ethnic and Migration Studies 42(7): $1115-1134$. 


\section{Tables and Figures}

TABLE 1. Self-reported workplace discrimination by demographic group.

\begin{tabular}{|c|c|c|c|c|c|}
\hline & $\%$ All & $\%$ Migrants & $\%$ Non-Migrants & $\%$ Men & $\%$ Women \\
\hline Racial/ethnic background & 1.5 & 6.7 & 0.7 & 1.7 & 1.3 \\
\hline Religion & 0.9 & 3.3 & 0.5 & 1.0 & 0.7 \\
\hline Nationality & 1.6 & 7.2 & 0.7 & 1.9 & 1.3 \\
\hline Total racial discrimination ${ }^{a}$ & 2.4 & 10.3 & 1.2 & 2.7 & 2.1 \\
\hline Sex-related & 1.8 & 1.8 & 1.8 & 0.8 & 2.9 \\
\hline Age-related & 3.2 & 2.8 & 3.3 & 3.0 & 3.5 \\
\hline Disability & 0.7 & 0.6 & 0.7 & 0.7 & 0.7 \\
\hline Sexual orientation & 0.4 & 0.3 & 0.4 & 0.4 & 0.3 \\
\hline Total discrimination & 6.7 & 13.0 & 5.7 & 6.1 & 7.4 \\
\hline$N=$ & 59,555 & 8,607 & 50,948 & 28,126 & 31,429 \\
\hline
\end{tabular}

NOTES. Weighted. Post-stratification and cross-national weights are applied meaning each country is represented in proportion to the size of its in-work population. ${ }^{a}$ Multiple reports of discrimination are not double counted. 
TABLE 2. Skill under-utilization and under-skilling.

\begin{tabular}{|c|c|c|c|c|}
\hline & $\begin{array}{c}\text { Skill } \\
\text { underutilization }\end{array}$ & $\begin{array}{c}\text { Skills } \\
\text { matched }\end{array}$ & $\begin{array}{l}\text { Under- } \\
\text { skilled }\end{array}$ & $n=$ \\
\hline A. Overall & 28.8 & 57.2 & 13.9 & 59,555 \\
\hline \multicolumn{5}{|l|}{ B. Discrimination } \\
\hline No discrimination reported & 28.6 & 57.9 & 13.5 & 55,326 \\
\hline Racial or ethnic background & 36.2 & 45.3 & 18.5 & 988 \\
\hline Religion & 32.4 & 48.6 & 19.1 & 581 \\
\hline Nationality & 36.4 & 48.0 & 15.5 & 1,108 \\
\hline Sex-related & 32.0 & 45.3 & 22.8 & 1,126 \\
\hline Age-related & 32.0 & 45.3 & 22.8 & 1,999 \\
\hline Disability & 25.1 & 50.3 & 24.6 & 470 \\
\hline Sexual orientation & 30.3 & 47.6 & 22.2 & 235 \\
\hline \multicolumn{5}{|l|}{ C. Selected characteristics } \\
\hline Non-migrant (domestic born) & 28.6 & 57.6 & 13.9 & 50,948 \\
\hline Migrant & 30.7 & 55.1 & 14.3 & 8,607 \\
\hline Male & 29.7 & 56.7 & 13.6 & 28,126 \\
\hline Female & 27.9 & 57.8 & 14.3 & 31,429 \\
\hline Age $16-24$ years & 28.2 & 49.9 & 21.9 & 4,483 \\
\hline Age 25-34 years & 30.3 & 54.8 & 14.9 & 13,065 \\
\hline Age $35-44$ years & 29.1 & 57.7 & 13.2 & 15,688 \\
\hline Age $45+$ years & 28.0 & 59.9 & 12.1 & 26,319 \\
\hline
\end{tabular}

NOTES. Row percentages, weighted. Selected variables linked to hypotheses. Full descriptive statistics are presented in the online appendix. 
TABLE 3. Age discrimination by age category

\begin{tabular}{lcccc}
\hline & $\mathbf{1 6 - 2 4} \mathbf{~ y r s}$ & $\mathbf{2 5 - 3 4} \mathbf{~ y r s}$ & $\mathbf{3 5 - 4 4} \mathbf{~ y r s}$ & $\mathbf{4 5 +}$ yrs \\
\hline \% reporting age discrimination & 7.5 & 2.9 & 1.5 & 3.6 \\
\% of total age discrimination & 21.5 & 20.1 & 12.5 & 45.9 \\
$N=$ & 4,483 & 13,065 & 15,688 & 26,319 \\
\hline
\end{tabular}

NOTES. Weighted. 
TABLE 4. Skill underutilization and training under-skilling: Average marginal effects

\begin{tabular}{|c|c|c|c|c|c|c|c|c|}
\hline (Base outcome= skills match duties) & $\begin{array}{c}\text { I. } \\
\text { Over-skilled }\end{array}$ & s.e. & $\begin{array}{c}\text { I. } \\
\text { Under-skilled }\end{array}$ & s.e. & $\begin{array}{c}\text { II. } \\
\text { Over-skilled }\end{array}$ & s.e. & $\begin{array}{c}\text { II. } \\
\text { Under-skilled }\end{array}$ & s.e. \\
\hline \multicolumn{9}{|l|}{ Model 1. Migrant status } \\
\hline Migrant & $0.021 * *$ & 0.005 & $0.009 *$ & 0.004 & $0.016^{* *}$ & 0.006 & $0.005 \mathrm{~ns}$ & 0.004 \\
\hline \multicolumn{9}{|l|}{ Model 2. Sex and job composition } \\
\hline Female & $-0.025 * *$ & 0.004 & $0.001 \mathrm{~ns}$ & 0.003 & $-0.019 * *$ & 0.005 & $-0.016 * *$ & 0.003 \\
\hline Job sex composition: Mostly female & - & & - & & $-0.09 \mathrm{~ns}$ & 0.005 & $0.008 *$ & 0.004 \\
\hline \multicolumn{9}{|l|}{ Model 3: Age $(0=16<25$ years $)$} \\
\hline $25<35$ years & $0.020 *$ & 0.008 & $-0.025 * *$ & 0.005 & $0.022 * *$ & 0.008 & $-0.049 * *$ & 0.005 \\
\hline $35<45$ years & $0.007 \mathrm{~ns}$ & 0.008 & $-0.040^{* * *}$ & 0.005 & $0.021 * *$ & 0.008 & $-0.064 * *$ & 0.005 \\
\hline $45+$ years & $-0.007 \mathrm{~ns}$ & 0.007 & $-0.062^{* *}$ & 0.005 & $0.025^{* *}$ & 0.008 & $-0.085^{* *}$ & 0.005 \\
\hline \multicolumn{9}{|c|}{ Models 4-10: Self-reported discrimination } \\
\hline Discrimination: Racial or ethnicity & $0.058 * *$ & 0.014 & $0.043 * *$ & 0.009 & $0.047^{*}$ & 0.014 & $0.043^{* *}$ & 0.009 \\
\hline Discrimination: Religious & $0.044 *$ & 0.018 & $0.036 * *$ & 0.012 & $0.032 \mathrm{~ns}$ & 0.018 & $0.041 * *$ & 0.012 \\
\hline Discrimination: Nationality & $0.070^{* *}$ & 0.013 & $0.032 * *$ & 0.009 & $0.056^{* *}$ & 0.013 & $0.032 * *$ & 0.009 \\
\hline Discrimination: Sex & $0.067 * *$ & 0.013 & $0.049 * *$ & 0.009 & $0.074 * *$ & 0.013 & $0.034 * *$ & 0.009 \\
\hline Discrimination: Age & $0.051 * *$ & 0.010 & $0.046^{* *}$ & 0.007 & $0.057^{* *}$ & 0.010 & $0.038 * *$ & 0.007 \\
\hline Discrimination: Disability & $0.031 \mathrm{~ns}$ & 0.021 & $0.050 * *$ & 0.013 & $0.037 \mathrm{~ns}$ & 0.021 & $0.053 * *$ & 0.013 \\
\hline Discrimination: Sexual orientation & $0.047 \mathrm{~ns}$ & 0.029 & $0.051 * *$ & 0.019 & $0.043 \mathrm{~ns}$ & 0.029 & $0.049 * *$ & 0.018 \\
\hline Control variables included? & - & & - & & Yes & & Yes & \\
\hline
\end{tabular}

Control variables included?

NOTES. Models for presented covariates estimated separately. Selected variables presented. See online appendix for full models. $*=\mathrm{p} .<0.05, * *=\mathrm{p} .<0.001,+\mathrm{p}$. $<0.1$
s.e. is standard error. Control variables are highest qualification, job tenure, occupation, industry, public sector, working hours, country, year, age (Models $1-2$ and $4-10$ )
sex (Models 1,3 and 4-10) and job sex composition (Model 2). 
TABLE 5. Skill under-utilization and under-skilling: Confounding effects (KHB Method)

\begin{tabular}{|c|c|c|c|c|c|c|}
\hline & Over-skilled & s.e. & $\begin{array}{c}\% \\
\text { Confounding }\end{array}$ & $\begin{array}{l}\text { Under- } \\
\text { skilled }\end{array}$ & s.e. & $\begin{array}{c}\% \\
\text { Confounding }\end{array}$ \\
\hline \multicolumn{7}{|l|}{ i. Migrant } \\
\hline Total & $1.14 * *$ & 0.03 & & $1.15 * *$ & 0.04 & \\
\hline Direct & $1.09 * *$ & 0.03 & & $1.08 *$ & 0.04 & \\
\hline Indirect (Difference) & $1.04 * *$ & 0.01 & 30.4 & $1.06 * *$ & 0.02 & 42.2 \\
\hline \multicolumn{7}{|l|}{ ii. Sex } \\
\hline Total & $0.87 * *$ & 0.02 & & $0.96 \mathrm{~ns}$ & 0.03 & \\
\hline Direct & $0.88 * *$ & 0.02 & & $0.82 * *$ & 0.03 & \\
\hline Indirect (Difference) & $0.996 \mathrm{~ns}$ & 0.01 & 3.3 & $1.17 * *$ & 0.02 & -423.0 \\
\hline \multicolumn{7}{|c|}{ iii. Discrimination: Racial/ethnic } \\
\hline Total & $1.46 * *$ & 0.11 & & $1.73 * *$ & 0.16 & \\
\hline Direct & $1.38 * *$ & 0.10 & & $1.68 * *$ & 0.16 & \\
\hline Indirect (Difference) & $1.06 * *$ & 0.02 & 15.3 & $1.03 \mathrm{~ns}$ & 0.03 & 5.5 \\
\hline \multicolumn{7}{|c|}{ iv. Discrimination: Religion } \\
\hline Total & $1.34 * *$ & 0.13 & & $1.58 * *$ & 0.19 & \\
\hline Direct & $1.27 *$ & 0.12 & & $1.60 * *$ & 0.20 & \\
\hline Indirect (Difference) & $1.06 * *$ & 0.02 & 20.2 & $0.99 \mathrm{~ns}$ & 0.03 & -2.5 \\
\hline \multicolumn{7}{|c|}{ v. Discrimination: Nationality } \\
\hline Total & $1.52 * *$ & 0.10 & & $1.55 * *$ & 0.14 & \\
\hline Direct & $1.42 * *$ & 0.10 & & $1.53 * *$ & 0.14 & \\
\hline Indirect (Difference) & $1.07 * *$ & 0.02 & 16.8 & $1.02 \mathrm{~ns}$ & 0.03 & 4.1 \\
\hline \multicolumn{7}{|l|}{ vi. Discrimination: Sex } \\
\hline Total & $1.55 * *$ & 0.11 & & $1.89 * *$ & 0.16 & \\
\hline Direct & $1.56 * *$ & 0.11 & & $1.61 * *$ & 0.14 & \\
\hline Indirect (Difference) & $0.99 \mathrm{~ns}$ & 0.01 & -1.53 & $1.18 * *$ & 0.03 & 25.3 \\
\hline \multicolumn{7}{|c|}{ vii. Discrimination: Age } \\
\hline Total & 1.42 & 0.07 & & $1.74 * *$ & 0.11 & \\
\hline Direct & 1.44 & 0.07 & & $1.63 * *$ & 0.11 & \\
\hline Indirect (Difference) & $0.98+$ & 0.01 & -4.6 & $1.07 * *$ & 0.02 & 12.2 \\
\hline \multicolumn{7}{|c|}{ viii. Discrimination: Disability } \\
\hline Total & $1.28 *$ & 0.14 & & $1.79 * *$ & 0.23 & \\
\hline Direct & $1.33 * *$ & 0.14 & & $1.84 * *$ & 0.24 & \\
\hline Indirect (Difference) & $0.96 *$ & 0.02 & -15.7 & $0.97 \mathrm{~ns}$ & 0.03 & -5.2 \\
\hline \multicolumn{7}{|c|}{ ix. Discrimination: Sexuality } \\
\hline Total & $1.40 * *$ & 0.21 & & $1.87 * *$ & 0.34 & \\
\hline Direct & $1.37 * *$ & 0.20 & & $1.78 * *$ & 0.33 & \\
\hline Indirect (Difference) & 1.02 & 0.02 & 7.1 & $1.05 \mathrm{~ns}$ & 0.05 & 7.6 \\
\hline
\end{tabular}

Relative Risk Ratios. Models for presented covariates estimated separately. Selected variables presented. See online appendix for full models. $*=$ p. $<0.05, * *=$ p. $<0.001,+$ p. $<0.1$. s.e. is standard error. Control variables are identical to models presented in Table 4 . 